\title{
Transthyretin: No association between serum levels or gene variants and schizophrenia
}

\author{
Dina Ruano a, António Macedo ${ }^{\mathrm{b}}$, Maria J. Soares ${ }^{\mathrm{b}}$, José Valente ${ }^{\mathrm{b}}$, Maria H. Azevedo ${ }^{\mathrm{b}}$, \\ Mara H. Hutz ${ }^{c}$, Clarissa S. Gama ${ }^{d}$, Maria I. Lobato ${ }^{d}$, Paulo Belmonte-de-Abreu ${ }^{d}$, \\ Ann B. Goodman ${ }^{\text {e, }}$ Carlos Pato ${ }^{\text {f,g }}$, Maria J. Saraiva ${ }^{\text {h }}$, Peter Heutink ${ }^{\text {i }}$, Joana A. Palha ${ }^{\text {a,* }}$ \\ ${ }^{\text {a }}$ Life and Health Sciences Research Institute (ICVS), School of Health Sciences, University of Minho, Campus de Gualtar, 4710-057 Braga, Portugal \\ ${ }^{\mathrm{b}}$ Instituto de Psicologia Médica, Faculdade de Medicina da Universidade de Coimbra, Coimbra, Portugal \\ ${ }^{\mathrm{c}}$ Departamento de Genética, Universidade Federal do Rio Grande do Sul, Porto Alegre, Brazil \\ ${ }^{d}$ Department of Psychiatry, Universidade Federal do Rio Grande do Sul, Porto Alegre, Brazil \\ e The Massachusetts Mental Health Center Academic Division of Public Psychiatry, Department of Psychiatry, \\ Beth Israel Deaconess Medical Center, Harvard Medical School, Boston, USA \\ ${ }^{\mathrm{f}}$ Center for Psychiatric and Molecular Genetics, Department of Psychiatry, State University of New York (SUNY), Syracuse, NY, USA \\ geterans Administration Medical Center, Washington, DC, USA \\ ${ }^{\mathrm{h}}$ Institute for Molecular and Cell Biology and ICBAS, University of Porto, Porto, Portugal \\ ${ }^{i}$ Department of Clinical Genetics and Human Genetics, VU University Medical Center, Amsterdam, The Netherlands
}

Received 7 November 2005; received in revised form 13 March 2006; accepted 4 April 2006

\begin{abstract}
It has been proposed that schizophrenia results from an environmental insult in genetically predisposed individuals. Environmental factors capable of modulating transcriptional activity and their carriers could link the genetic and environmental components of schizophrenia. Among these is transthyretin (TTR), a major carrier of thyroid hormones and retinol-binding protein (RBP). Retinoids and thyroid hormones regulate the expression of several genes, both during development and in the adult brain. Decreased TTR levels have been reported in the cerebrospinal fluid of patients with depression and Alzheimer's disease, and the absence of TTR influences behavior in mice. DNA variants capable of altering TTR ability to carry its ligands, either due to reduced transcription of the gene or to structural modifications of the protein, may influence development of the central nervous system and behavior. In the present study we searched for variants in the regulatory and coding regions of the $T T R$ gene, and measured circulating levels of TTR and RBP. We found a novel single nucleotide polymorphism (SNP), ss46566417, 18 bp upstream of exon 4. Neither this SNP nor the previously described rs1800458 were found associated with schizophrenia. In addition, serum TTR and RBP levels did not differ between mentally healthy and schizophrenic individuals. In conclusion, our data does not support an involvement of the TTR gene in the pathophysiology of schizophrenia.
\end{abstract}

(C) 2006 Elsevier Ltd. All rights reserved.

Keywords: Transthyretin; Retinol-binding protein; Schizophrenia; Thyroid hormones; Retinoids; Association studies

\section{Introduction}

Schizophrenia is a complex neurodevelopment disorder (Beckmann, 1999). Epidemiological studies indicate an

\footnotetext{
${ }^{*}$ Corresponding author. Tel.: +351 253604817; fax: +351 253604809.

E-mail address: japalha@ecsaude.uminho.pt (J.A. Palha).
}

increased risk for developing schizophrenia in relatives of probands with the disease (Gottesman, 1991), suggesting a genetic predisposition. However, monozygotic twins are frequently phenotypically discordant, which implies that environmental factors must play a role in the disease etiology (Tsuang et al., 2001). 
Thyroid hormones and retinoids are among the environmental factors proposed to be altered in schizophrenia (Goodman, 1998; Palha and Goodman, 2005). It is widely recognized that thyroid hormones and retinoids are essential for the normal development of the central nervous system, and that lack of adequate levels during pregnancy leads to several neurological defects (Lane and Bailey, 2005; Luo et al., 2004; Morreale de Escobar, 2003; Morreale de Escobar et al., 2004; Wietrzych et al., 2005). Thyroid hormones and retinoids act as modulators of the expression of several genes through the binding of retinoic acid and triiodothronine to the corresponding nuclear receptors. Interestingly, evidence of altered retinoid and thyroid hormone metabolisms in schizophrenic patients is arising from studies in postmortem brains, in which RAR $\alpha$ and myelin-basic protein, genes whose expression is regulated by thyroid hormones and retinoids, were found to have altered expression (Hakak et al., 2001; Rioux and Arnold, 2005).

By influencing ligand availability, carriers of thyroid hormones and retinoids indirectly regulate the transcription of several genes. Among the modulators of thyroid hormone and retinoid availability is transthyretin (TTR), a major carrier of thyroxine and retinol [through association with (RBP)], both in serum and in cerebrospinal fluid (CSF) (Palha, 2002). TTR has been implicated in behavior: decreased TTR CSF levels were found in patients with depression (Sullivan et al., 1999) and with Alzheimer's disease (Serot et al., 1997). Whether this decrease is the result or a consequence of the disease or whether it is caused by medication is still unclear. Supporting that both processes might be implicated in behavior are the observations that TTR-null mice (Palha 2002) present increased motor activity in behavior tests that address anxiety-like and depression-like behaviors (Sousa et al., 2004), and that clozapine treatment induces TTR expression in the brain (Chen and Chen, 2005).

The TTR gene is a single copy gene, on $18 \mathrm{q} 12.1$, composed of four exons (Tsuzuki et al., 1985) that encodes a $14 \mathrm{kDa}$ subunit which assembles as a tetramer (Blake et al., 1978). Whereas plasma TTR originates primarily from the liver, CSF TTR is mainly produced and secreted from the choroid plexus, where it represents about $20 \%$ of the total protein synthesis (Aldred et al., 1995). The observation that homologues of the TTR protein can be found in a wide range of species (Eneqvist et al., 2003) and that its synthesis starts early during embryonic development (Larsen and DeLallo, 1989), suggests a relevant role for TTR in development.

These observations, prompted us to investigate the TTR gene as a candidate gene in schizophrenia. In the present study we searched for variants in the regulatory and coding regions of the $T T R$ gene, and association between the polymorphisms detected and schizophrenia were analyzed in three different samples. We also investigated serum TTR and RBP levels in schizophrenic and in mentally healthy individuals.

\section{Materials and methods}

\subsection{Samples}

Two case-control samples were used: one from Portugal-mainland and a second from Brazil. A total of 244 unrelated schizophrenic patients (175 males and 69 females) and 210 controls (131 males and 79 females) were recruited from the north and center of Portugal-mainland. The Brazilian sample consisted of 69 cases and 85 controls, all unrelated males living in the area of Porto Alegre. A third, independent sample composed of 73 patients $(47$ males and 26 females) and their parents from the Azorean Islands (Portugal), was used for family-based association analysis. All subjects were of European ancestry. All participants gave informed consent for genetic studies and ethic committees of the institutions involved approved the study.

All patients from Portugal-mainland and Azorean Islands, as well as $45 \%$ of Portugal-mainland controls and $67 \%$ of the Azorean parents were evaluated using the Diagnostic Instrument for Genetic Studies (DIGS) (Nurnberger et al., 1994), a semi-structured interview that assesses the criteria for schizophrenia and other psychiatric diseases. The diagnosis was made based on the Diagnostic and Statistical Manual of Mental Disorders, review of the third edition (DSM-IIIR, 1985) (American Psychiatric Association, 1987). All Brazilian patients were classified using the Operational Checklist for Psychotic Disorders (OPCRIT) (McGuffin and Farmer, 2001). No psychological assessment interviews have been conducted in the remaining Portuguese mainland controls (students and tissue donors) or Azorean parents, or in any of the Brazilian controls (blood donors).

\subsection{Polymorphism screening}

Using single strand conformational polymorphism (SSCP) analysis, a sub-sample of 60 patients from the Portuguese mainland was used for screening variants in all four exons and adjacent splicing sites, as well as in the promoter and the $3^{\prime}$ untranslated regions. For this analysis the PCR products were subjected to electrophoresis on a nondenaturing polyacrylamide gel under two temperature conditions: $4{ }^{\circ} \mathrm{C}$ and $25^{\circ} \mathrm{C}$. After completion of the electrophoresis, band patterns were visualized with silver staining, using standard protocols. PCR products from subjects displaying altered band patterns in the SSCP analyses were sequenced in both directions. The sequencing reactions were performed using the BigDye Sequencing Kit 3.1 and run on the 3700 sequencer, both from Applied Biosystems (Foster City, CA).

The TTR sequence was obtained from the GenBank Data Libraries (Accession No. M11844) and the Primer3 program (Rozen and Skaletsky, 2000) was used for primer design. Primer sequences are available upon request. 


\subsection{SNP genotyping}

Two single nucleotide polymorphisms (SNP) (rs1800458 on exon 2 and ss46566417 on intron 3) were detected (Fig. 1). These two SNPs were further typed for association in the complete samples described above.

Detection of rs 1800458 and ss46566417 was based upon analysis of primer extension products generated from previously amplified genomic DNA, using a chip-based MALDI-TOF mass spectrometry platform (SEQUENOM Inc., San Diego, CA). PCR primers with a universal (10 bp) sequence at the $5^{\prime}$ end (5'-ACGTTGGATG-3') and the extension primer were created using the MassARRAY Assay Design 2.0 software (SEQUENOM), following manufacturer's instructions. For the MALDI-TOF analysis, aliquots of the samples were spotted onto a SpectroCHIP (SEQUENOM). Mass spectra were generated by the MassARRAY spectrometer (SEQUENOM). Genotypes were automatically determined using the SpectroTYPER software (SEQUENOM). In some cases genotyping of rs1800458 was repeated using PCR-based restriction fragment length polymorphism assay. The same PCR product used for the SSCP analysis was digested with the endonuclease $C f r$ 10I (Fermentas, Vilnius, Lithuania). The digested reactions were resolved by electrophoresis on $3 \%$ agarose gels.

\subsection{Measurement of TTR and RBP serum levels}

Twenty-six schizophrenic patients (16 males and 10 females) and 54 controls ( 25 males and 29 females) from Portugal-mainland as well as 27 schizophrenic patients (15 males and 12 females) from the Azorean Islands were used to measure the serum levels of TTR, RBP, and albumin. Serum TTR, RBP, and albumin were determined by radial-immunodiffusion in accordance to the manufacturer's instructions (The Binding Site Limited, Birmingham, UK).

\subsection{Statistical analysis}

The genotype and allele frequencies were compared between cases and controls using a standard $\chi^{2}$ test, calcu- lated by SPSS (version 13.0). Hardy-Weinberg equilibrium (HWE) was assessed in the same way.

To analyze the results of the family-based association study (Azorean sample), a transmission disequilibrium test (TDT) was performed, using TRANSMIT version 2.5.4 (Clayton, 1999).

Student's $t$ test was used to compare ages and protein serum levels between patients and controls. Association between serum TTR, RBP and albumin levels and their correlation with age was analyzed by linear regression. These last two analyses were also performed with SPSS. For all tests, the results were considered significant when the $P$-value was less than $5 \%$.

\section{Results}

\subsection{Association study}

In the 60 patients screened for variants we detected the presence of two SNPs: the previously described rs 1800458 on exon 2 and the novel ss46566417, 18 bp upstream from exon 4 (Fig. 1). The novel SNP has been submitted to the NCBI SNP database (http://www.ncbi.nlm.nih.gov/SNP/).

HWE was verified for all tested samples, showing no deviation for either SNP analyzed (Table 1). Table 1 summarizes the genotyping results for the two SNPs. No significant differences between cases and controls were detected in genotype or allele frequencies, either in the Portuguese mainland or in the Brazilian samples. The lack of association was confirmed in the Azorean sample, since the TDT revealed no excess of transmission from parents to offspring (Table 2).

\subsection{TTR, RBP and albumin serum levels}

Serum levels of TTR, RBP and albumin did not differ between schizophrenic and mentally healthy individuals, whether male or female. There were no statistical differences of TTR, RBP or albumin serum levels between the analyzed Portuguese mainland and Azorean patients. Therefore these values are presented together in Table 3. Distribution of age in the sample used was not well matched between patients and controls (Table 3). How-

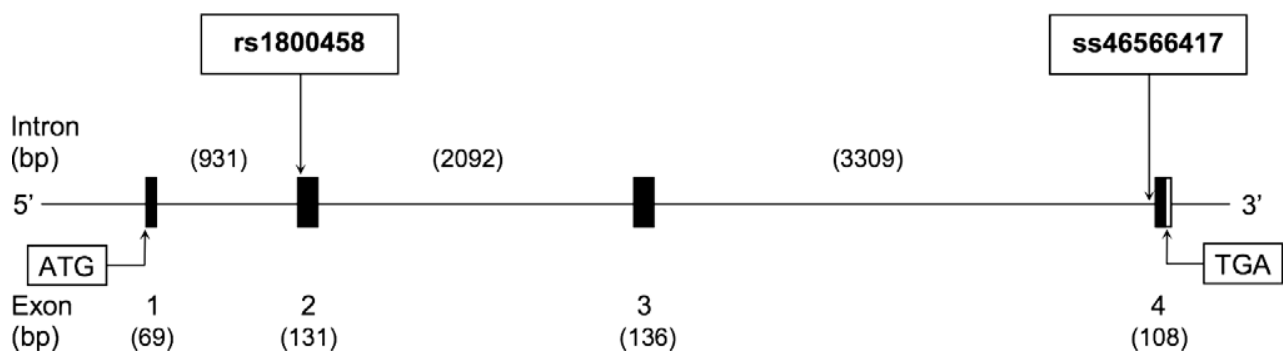

Fig. 1. Genomic structure of human TTR gene and locations of the two SNPs analyzed. Black boxes represent protein-coding regions, white boxes represent untranslated regions. Locations of initiation (ATG) and stop (TGA) codons and sizes of introns and exons are also provided. The rs and ss numbers identify the SNPs according with the dbSNP database of NCBI (http://www.ncbi.nlm.nih.gov/SNP/). 
Table 1

Case-control analyses for the two SNPs studied

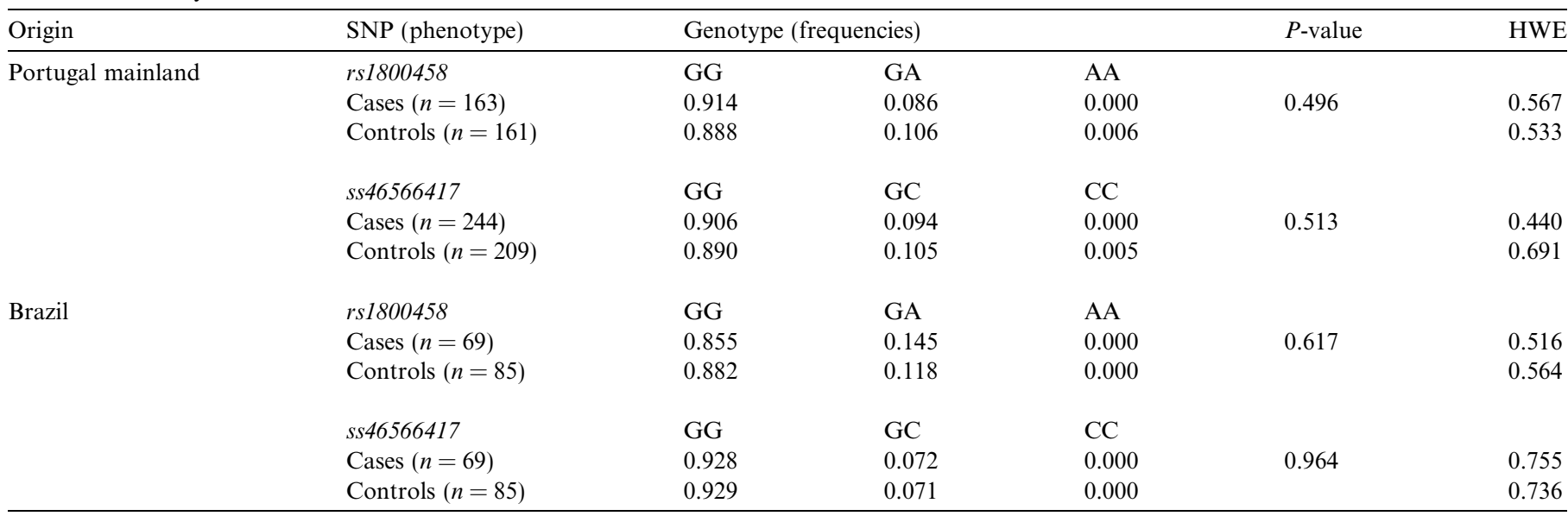

Represented are the genotype frequencies, $P$-values and HWE values.

Table 2

Individual SNP analysis by TRANSMIT

\begin{tabular}{llll}
\hline SNPs & Major $>$ minor allele $\left(\right.$ frequency $\left.{ }^{\mathrm{a}}\right)$ & $\chi^{2}(\mathrm{df}=1)$ & $P$-value \\
\hline rs1800458 & $\mathrm{G}>\mathrm{A}(0.034)$ & 0.517 & 0.472 \\
ss46566417 & $\mathrm{G}>\mathrm{C}(0.045)$ & 0.077 & 0.782 \\
\hline
\end{tabular}

${ }^{\text {a }}$ Frequency of the minor allele, produced by the TRANSMIT program.

ever, within this age-range, age did not influence the levels of TTR, RBP and albumin, as verified by linear regression analysis $(P$-value $=0.176$ for TTR, $P$-value $=0.330$ for RBP and $P$-value $=0.736$ for albumin). As expected, TTR and RBP levels were positively correlated, when analyzed by linear regression $(P<0.0005)$.

\section{Discussion}

In the present study we describe a novel $T T R$ polymorphism, ss 46566417 with an allele frequency of 0.048 in Caucasians [0.052 (47/906) in Portuguese from mainland, 0.048 $(14 / 292)$ in Azorean, and 0.036 (11/308) in Brazilian]. This novel polymorphism does not change the amino-acid sequence of the protein, since it is localized on intron 3, but might interfere with transcription given its close proximity to a splicing site. We also detected the SNP rs 1800458 at an allele frequency (0.059) similar to that previously described in the Caucasian population (Jacobson et al., 1995). Neither of these two SNPs was found associated with schizophrenia. While the present study, as many others, failed to identify genetic variants that predispose to schizophrenia, recent studies in brains from schizophrenic patients have shown altered expression of several genes (Hakak et al., 2001; Mirnics et al., 2000). Such alterations might result from variants in the regulatory regions of the genes but also from inadequate availability of transcription modulators such as hormones and vitamins (Palha and Goodman, in press). For these reasons, and even though we failed to detect association of the TTR polymorphisms with schizophrenia, in these two populations, we investigated the circulating levels of TTR and also of RBP. Serum levels of RBP did not differ between schizophrenic and mentally healthy individuals. Being the only plasma carrier for retinol, RBP is measured as a surrogate marker of retinol in the circulation (de Pee and Dary, 2002). Therefore, our data suggest that serum retinoid status is not altered in patients diagnosed with schizophrenia, since retinol is the most common form of retinoids in circulation. This is, however, in contrast with another study in which the serum levels of RBP and other inflammatory acute phase proteins such as albumin were found decreased in the serum of Chinese schizophrenic patients from Singapore (Wong et al., 1996). Given that our patient sample showed normal albumin serum levels, and since RBP is a useful marker of protein malnutrition (de Pee and Dary, 2002) and of inflammatory acute phase response (Fleck, 1989), it is possible that the values observed in that study might reflect a

Table 3

TTR, RBP and albumin serum levels in patients and in controls

\begin{tabular}{|c|c|c|c|c|c|c|}
\hline & \multicolumn{2}{|l|}{ Males } & \multirow[t]{2}{*}{$P$-value } & \multicolumn{2}{|l|}{ Females } & \multirow[t]{2}{*}{$P$-value } \\
\hline & Cases & Controls & & Cases & Controls & \\
\hline$N$ & 31 & 25 & & 22 & 29 & \\
\hline TTR (mg/L) & $296.9 \pm 49.4$ & $295.4 \pm 34.6$ & 0.898 & $277.0 \pm 51.1$ & $284.3 \pm 49.5$ & 0.610 \\
\hline RBP (mg/L) & $67.8 \pm 16.3$ & $65.4 \pm 9.9$ & 0.495 & $64.9 \pm 13.9$ & $61.8 \pm 13.4$ & 0.427 \\
\hline Albumin $(\mathrm{g} / \mathrm{L})$ & $42.8 \pm 5.6$ & $43.9 \pm 5.8$ & 0.473 & $41.0 \pm 4.4$ & $41.2 \pm 4.9$ & 0.906 \\
\hline
\end{tabular}

Data represented as means $\pm \mathrm{SD}$. 
particular nutritional or inflammatory state in the patients. While we found no changes in RBP circulating levels in our patient population, search for RBP variants should be investigated since these could impair the ability to carry retinol and/or to bind to TTR.

Ours is the first report on serum levels of TTR and we found no differences between schizophrenic and control individuals. It should be noted that serum TTR levels do not necessarily reflect CSF levels since the first is mainly derived form the liver while the latter is primarily synthesized and secreted from the choroid plexus (Aldred et al., 1995). In fact, TTR expression has been described as differentially regulated in the liver and in the choroid plexus (Dickson et al., 1986); probably due to the presence of tissue specific transcription factors (Costa et al., 1990). Recent interest on the possible decrease of CSF TTR during aging has been raised mainly in the context of Alzheimer's disease, since TTR is also able to bind the Alzheimer $\beta$ peptide (Carro et al., 2005). It would therefore be interesting to measure CSF TTR levels in patients, where available, to extend a single study in which CSF TTR levels were reported normal in patients with schizophrenia (Bock, 1978). All together the data obtained to date does not support the involvement of TTR in the pathophysiology of schizophrenia. However, it is important to investigate whether $T T R$ polymorphisms are related to any particular symptom or response to medication, or whether the levels of TTR ligands, rather than TTR itself, are involved in the etiology of schizophrenia.

\section{Acknowledgements}

We thank Martine van Belzen and Paul Moreira for technical support and all the subjects for their participation in this study. This work was supported by Grant POCTI/ 35837/MGI/2000 from Fundação para a Ciência e a Tecnologia/FEDER. Dina Ruano is a recipient of a fellowship (SFRH/BD/8659/2002) from Fundação para a Ciência e a Tecnologia (FCT), Portugal.

\section{References}

Aldred AR, Brack CM, Schreiber G. The cerebral expression of plasma protein genes in different species. Comparative Biochemistry and Physiology B Biochemistry and Molecular Biology 1995;111:1-15.

American Psychiatric Association. Diagnostic and statistical manual of mental disorders, 3rd revised edition (DSM-III-R). Washington, DC: American Psychiatric Association; 1987.

Beckmann H. Developmental malformations in cerebral structures of schizophrenic patients. European Archives of Psychiatry and Clinical Neuroscience 1999;249(Suppl 4):44-7.

Blake CC, Geisow MJ, Oatley SJ, Rerat B, Rerat C. Structure of prealbumin: secondary, tertiary and quaternary interactions determined by Fourier refinement at 1.8 A. Journal of Molecular Biology 1978;121:339-56.

Bock E. Immunoglobulins, prealbumin, transferrin, albumin, and alpha2macroglobulin in cerebrospinal fluid and serum in schizophrenic patients. Birth Defects: Original Article Series 1978;14:283-95.

Carro E, Trejo JL, Gerber A, Loetscher H, Torrado J, Metzger F, et al. Therapeutic actions of insulin-like growth factor I on APP/PS2 mice with severe brain amyloidosis. Neurobiology of Aging 2005. doi:10.1016/j.neurobiolaging.2005.06.015.

Chen ML, Chen $\mathrm{CH}$. Comparative proteome analysis revealed upregulation of transthyretin in rat brain under chronic clozapine treatment. Journal of Psychiatric Research 2005. doi:10.1016/ j.jpsychires.2005.04.006.

Clayton D. A generalization of the transmission/disequilibrium test for uncertain-haplotype transmission. American Journal of Human Genetics 1999;65:1170-7.

Costa RH, Van Dyke TA, Yan C, Kuo F, Darnell Jr JE. Similarities in transthyretin gene expression and differences in transcription factors: liver and yolk sac compared to choroid plexus. Proceedings of the National Academy of Sciences of the United States of America 1990;87:6589-93.

de Pee S, Dary O. Biochemical indicators of vitamin A deficiency: serum retinol and serum retinol binding protein. Journal of Nutrition 2002:132:2895S-901S.

Dickson PW, Aldred AR, Marley PD, Bannister D, Schreiber G. Rat choroid plexus specializes in the synthesis and the secretion of transthyretin (prealbumin). Regulation of transthyretin synthesis in choroid plexus is independent from that in liver. Journal of Biological Chemistry 1986;261:3475-35478.

Eneqvist T, Lundberg E, Nilsson L, Abagyan R, Sauer-Eriksson AE. The transthyretin-related protein family. European Journal of Biochemistry $2003 ; 270: 518-32$.

Fleck A. Clinical and nutritional aspects of changes in acute-phase proteins during inflammation. Proceedings of the Nutrition Society 1989;48:347-54.

Goodman AB. Three independent lines of evidence suggest retinoids as causal to schizophrenia. Proceedings of the National Academy of Sciences of the United States of America 1998;95:7240-4.

Gottesman II. Schizophrenia genesis: the origins of madness. New York: WH Freeman \& Co; 1991.

Hakak Y, Walker JR, Li C, Wong WH, Davis KL, Buxbaum JD, et al. Related genome-wide expression analysis reveals dysregulation of myelination-related genes in chronic schizophrenia. Proceedings of the National Academy of Sciences of the United States of America 2001;98:4746-51.

Jacobson DR, Alves IL, Saraiva MJ, Thibodeau SN, Buxbaum JN. Transthyretin Ser 6 gene frequency in individuals without amyloidosis. Human Genetics 1995;95:308-12.

Lane MA, Bailey SJ. Role of retinoid signalling in the adult brain. Progress in Neurobiology 2005;75:275-93.

Larsen PD, DeLallo L. Cerebrospinal fluid transthyretin in the neonate and blood-cerebrospinal fluid barrier permeability. Annals of Neurology 1989;25:628-30.

Luo T, Wagner E, Crandall JE, Drager UC. A retinoic-acid critical period in the early postnatal mouse brain. Biological Psychiatry 2004;56:971-80.

McGuffin P, Farmer A. Polydiagnostic approaches to measuring and classifying psychopathology. American Journal of Medical Genetics 2001;105:39-41.

Mirnics K, Middleton FA, Marquez A, Lewis DA, Levitt P. Molecular characterization of schizophrenia viewed by microarray analysis of gene expression in prefrontal cortex. Neuron 2000;28:53-67.

Morreale de Escobar G. Maternal hypothyroxinemia versus hypothyroidism and potential neurodevelopmental. Alterations of her offspring. Annales d'Endocrinologie 2003;64:51-2.

Morreale de Escobar G, Obregon MJ, Escobar del Rey F. Role of thyroid hormone during early brain development. European Journal of Endocrinology 2004;151(Suppl 3):25-37.

Nurnberger Jr JI, Blehar MC, Kaufmann CA, York-Cooler C, Simpson SG, Harkavy-Friedman $\mathrm{J}$, et al. Diagnostic interview for genetic studies. Rationale, unique features, and training. NIMH genetics initiative. Archives of General Psychiatry 1994;51:849-59.

Palha JA. Transthyretin as a thyroid hormone carrier: function revisited. Clinical Chemistry and Laboratory Medicine 2002;40:1292-300 
Palha JA, Goodman AB. Thyroid hormones and retinoids: a possible link between genes and environment in schizophrenia. Brain Research Reviews 2005. doi:10.1016/i.brainresrev.2005.10.001.

Rioux L, Arnold SE. The expression of retinoic acid receptor alpha is increased in the granule cells of the dentate gyrus in schizophrenia. Psychiatry Research 2005;133:13-21.

Rozen S, Skaletsky H. Primer3 on the WWW for general users and for biologist programmers. Methods in Molecular Biology 2000;132: $365-86$.

Serot JM, Christmann D, Dubost T, Couturier M. Cerebrospinal fluid transthyretin: aging and late onset Alzheimer's disease. Journal of Neurology Neurosurgery and Psychiatry 1997;63:506-8.

Sousa JC, Grandela C, Fernandez-Ruiz J, de Miguel R, de Sousa L, Magalhaes AI, et al. Transthyretin is involved in depression-like behaviour and exploratory activity. Journal of Neurochemistry 2004;88:1052-8.
Sullivan GM, Hatterer JA, Herbert J, Chen X, Roose SP, Attia E, et al. Low levels of transthyretin in the CSF of depressed patients. American Journal of Psychiatry 1999;156:710-5.

Tsuang MT, Stone WS, Faraone SV. Genes, environment and schizophrenia. British Journal of Psychiatry Supplement 2001;40: s18-24.

Tsuzuki T, Mita S, Maeda S, Araki S, Shimada K. Structure of the human prealbumin gene. Journal of Biological Chemistry 1985;260: 12224-7.

Wietrzych M, Meziane H, Sutter A, Ghyselinck N, Chapman PF, Chambon $\mathrm{P}$, et al. Working memory deficits in retinoid $\mathrm{X}$ receptor gamma-deficient mice. Learning and Memory 2005;12: 318-26.

Wong CT, Tsoi WF, Saha N. Acute phase proteins in male Chinese schizophrenic patients in Singapore. Schizophrenia Research 1996;22: 165-71. 